\title{
Correspondence
}

\section{Tardive dyskinesia: risk disclosure and informed consent in the Netherlands}

Sir: We read with interest the article of Chaplin \& Potter (Psychiatric Bulletin. December 1996, 20. 714-716) on the practice of screening and risk disclosure in patients at risk of developing tardive dyskinesia in the UK. We have conducted a similar study in the Netherlands. A questionnaire was sent to 200 consultant psychiatrists on the Central College mailing list, enquiring about their current practice towards informing their patients on neuroleptic medication about the long-term risks of tardive dyskinesia. One hundred and six (56\%) questionnaires were returned, $90 \%$ from general psychiatrists. Of the respondents, $20 \%$ always and $75 \%$ sometimes discuss the risk of tardive dyskinesia with patients being commenced on neuroleptic treatment, despite the fact that $65 \%$ believe it not to be in the patient's best interests to know about the risk of tardive dyskinesia.

It was agreed by $75 \%$ of respondents that most psychotic patients receiving ongoing treatment with neuroleptic drugs are capable of informed decisions regarding their medication. Possible future litigation was a concern for $60 \%$ of those responding, while only $40 \%$ would support using a standardised consent form.

Our study shows that Dutch psychiatrists are less reluctant to discuss the risk of tardive dyskinesia with their patients, although they share similar concerns regarding this issue with their British counterparts.

Clearly patients need to know the likely effects and side-effects of medication and possible options. There is evidence that many patients want more information than they currently receive (Rogers et al, 1993).

Brabbins et al (1996) felt that the use of a proforma would facilitate the process of informed consent. The majority of respondents in our survey do not favour the use of a consent form informing patients of the risk of tardive dyskinesia. This is in line with the recommendations of the American Psychiatric Association (1992) which argue that the use of a consent form could militate against the ongoing process of informed consent.

Whether in practice conditions conducive to a process of ongoing informed consent are created for these patients and accurately documented is more doubtful.
AMERICAN PSYCHIATRIC ASSOCIATION (1992) Tardive Dyskinesia: A Task Force Report of the American Psychiatric Association. Washington, DC: American Psychiatric Press.

Brabisns, C., Butler, J. \& Bentall, R. (1996) Consent to neuroleptic medication for schizophrenia: clinical ethical and legal issues. British Journal of Psychiatry. 168, 540-544.

Rogers, A., Pilgrim, D. \& LACEy, R. (1993) Experlencing Psychiatry: Users' Views of Services. London: Macmillan/MIND Publications.

Walter Pierre Bouman, Department of Health Care of the Elderly, University Hospital, Nottingham NG7 2UH; and JON ARCELUS-ALONSO, Northern General Hospital, Sheffield S5 7AU

\section{Evidence based medicine}

Sir: Schmidt et al (Psychiatric Bulletin. December 1996, 20, 705-707) outlined the growing influence of evidence based medicine (EBM) in medical practice and its implications for psychiatry. EBM has the potential to offer some hope in rationalising the current ad hoc chaos of the publication paper chase. Bearing in mind that $80 \%$ of all published scientific papers are never cited more than once and 5-20\% of citations are authors citing themselves (Institute for Scientific Information, 1990), emphasising training in research appraisal seems entirely appropriate. Successfully integrating the art of medicine with its psychosocial and philosophical facets with the rigours of scientific methodology is a training challenge in which EBM may have a place.

Higher psychiatric training, in providing protected research time and special interest sessions, leads the way in facilitating the incorporation of new knowledge into the expertise of SpR grades. Should purchasing and other new NHS structures seek to reduce our training freedom to become familiar with tools such as EBM, such pressure must be vigorously resisted. As a result, I hope to continue to be informed on diverse topics such as recruitment to drug trials (Skerrit et al, 1996) and the benefits of poetry (Holmes, 1996), both of which I consider will improve my clinical practice.

HOLMES, J. (1996) Can poetry help us become better psychiatrists? Psychiatric Bulletin, 20, 722-725.

INSTITUTE FOR SCIENTIFIC INFORMATION IN PHILADELPHIA (1990) Science, 250, 1331-1332. 